\title{
Move to Improve: Increasing Intellectual Control During a Physical Move
}

\author{
By Katrina Windon and Amy L. Allen
}

\begin{abstract}
This case study explores how efforts to simultaneously implement a new content management system and a storage management system while preparing and physically moving materials to a new high-density, off-site facility provided unique opportunities and challenges for improving intellectual control of archival materials at the University of Arkansas Special Collections. The authors explore their decisionmaking process and subsequent outcomes, while offering advice for institutions approaching similar projects.
\end{abstract}

\section{Introduction}

While moving a physical collection and implementing a new content management system can be daunting tasks on their own, they do not have to be mutually exclusive processes. A physical move can be used as an opportunity to create order rather than chaos. The University of Arkansas Libraries Special Collections made a commitment to improve intellectual control over its holdings by implementing both the content management system ArchivesSpace and the inventory management system CaiaSoft while preparing and moving physical materials to a new high-density, off-site facility. The two processes became completely interconnected, with the physical move providing the final impetus needed to attain necessary funding and institutional support for a hosted ArchivesSpace instance. Special collections staff used this opportunity to completely transform its management of physical collections, digital accession records, and finding aids. Managing and integrating these two large, interdepartmental projects simultaneously required detailed planning, coordinating staff from multiple departments, and quickly adapting to changes.

\section{Background}

\section{Institution and Library Background}

The University of Arkansas was established in 1871 under the Morrill Land Grant Act. The university is classified as a Research 1 (R1) university by the Carnegie Foundation for the Advancement of Teaching. The flagship campus in Fayetteville has seen steady enrollment growth, with a significant increase over the last 20 years, during which the student population almost doubled. The libraries have expanded multiple times over the years to keep pace with this growth.

The University of Arkansas Libraries opened a new high-density, off-site storage facility in 2018. At that time, the student population was 27,778 , the libraries held approximately 2.5 million volumes, and special collections held over 25,000 linear feet 
of manuscript materials. Mullins Library, the current main library building on campus, opened in 1968 with an original book capacity of 850,000 volumes and served a population of approximately 10,500 students. Over the years, the libraries used multiple tactics to keep pace with growth, including expanding the main library, opening branch libraries, and using other storage spaces on campus. Then, in 2005, a dedicated off-site storage building was opened, offering an additional 30,500 linear feet of shelving for volumes and 12,500 linear feet for manuscript boxes. The building was used for storing materials from both the main circulating collection and special collections.

\section{Plans for Renovation and a New Off-site Storage Building}

As collection growth again challenged the limits of the 2005 building, the administration decided to build a new high-density, off-site storage facility. Administrators began talks with architects and builders in 2015, planning for a completion date of 2018. After completion, the majority of collection materials would be moved off-site so that Mullins Library could undergo a much-needed asbestos abatement and remodel to add study spaces.

While the physical spaces in special collections would not be renovated at this time, staff took this opportunity to re-evaluate its onsite storage spaces to determine which manuscript collections should remain onsite and which could be moved off-site. Libraries administration had determined that hiring professional movers would be the most effective approach for handling the physical transfer of materials; however, special collections staff had to complete a tremendous amount of preparatory work for the move to be successful.

\section{Improving Intellectual Control during Major Transitions}

During this move, special collections staff committed to improving intellectual control of the collections to ensure that every archival collection was recorded in a unified database. Staff had the added challenge of drastic staffing and leadership changes during this period. The head of special collections accepted a position at another institution in 2015, and the first interim head resigned in February 2017. The dean of the libraries then assumed the position of interim head until a permanent replacement came onboard in July 2017. During this period, the number of full-time, permanent staff shrank from 12 to 7 , meaning that all staff had to take on extra duties in the dayto-day running of the department until replacements were eventually hired. The staff members directly supervising both the physical move and the ArchivesSpace implementation were included among the staff changes. The first portion of move planning was directed by the manuscripts unit head and a support staff archival manager in a one-year contract position. After both these staff members left, a new hire would manage these tasks.

During this time, staff would undergo the daunting task of preparing both the digital records for import into a new system and the physical collections for a move to a new building. While these two tasks might seem separate, they were actually interdependent 
with circumstances from each project affecting decisions for the other. While off-site storage was nothing new to special collections, space management and circulation protocols for materials stored in the new building would be fundamentally different. In the first off-site storage building, manuscript materials were stored by collection; however, in the new high-density storage, materials would be arranged by size and retrieved by barcode (as is common in other "Harvard-model" facilities ${ }^{1}$ ). As none of the special collections manuscript materials were barcoded at the time, for every container being moved, staff needed to record collection information, container size, and barcode. This project involved over 13,800 linear feet of collections at the existing off-site storage facility plus the collections moved from the main library. Having an all-inclusive database became not only desirable but absolutely essential to locate materials. In addition, the new off-site storage facility would function with specialized space management software to assign locations for later retrieval. For these reasons, ArchivesSpace and the new space management software, which had not been chosen when this process began, would need to work together. Timelines and decisions for both the move and ArchivesSpace implementation would directly affect each other.

\section{Selected Literature Review}

The experiences of others can provide advice and encouragement for what can seem like an overwhelming task. There is much discussion in the existing library and archival literature about moving collections and implementing content management systems; however, these are primarily presented as separate processes. Similarly, the literature addressing physical moves reflects a struggle to maintain current levels of description without simultaneously implementing improvements. Information on physical moves can be found in a variety of formats, from books and journal articles, to more informal formats such as blog posts.

In "Moving a Large Collection Quickly: A Study in Chaos," Goldberg and Sproles describe the four-month process to move or shift approximately 355,000 items at the University of Louisville during a library renovation designed to address a growing student population. ${ }^{2}$ While not dealing specifically with archives or special collections, the authors present lessons that can be applied to other moves. One lesson learned was that "time determines processing style, not the reverse."3 To meet the short timeline, staff members were reallocated, and all but essential functions were temporarily abandoned. "The construction timeline trumped more methodical and thoughtful handling," the authors report, and the staff was forced to prioritize speed over accuracy. The forced speed of the project resulted in failures in item tracking and up-to-date recordkeeping, which necessitated extensive data cleanup after the move.

Patricia Thibodeau describes the move of a hybrid library and archives collection within a similar timeline for the Duke University Medical Center Library and Archives. ${ }^{5}$ With the decision to expand the health system into the library's top floor, the staff had only five months to relocate the collections stored there. The author states that while the move did not resolve interior design and infrastructure deficiencies, it did follow a 
previously made recommendation to consolidate stacks to provide more study space, and it instituted a reallocation of resources to retrieve materials off-site.

Hoelscher and Cahalan focus on the positive aspects of moving a collection in their article "Rethinking Special Collections Moves as Opportunities, not Obstacles." ${ }^{6}$ The purpose of their move was to address preservation concerns, and the move took place in a relatively short time frame, with the planning beginning in spring 2016 and the move completed in summer 2017. The move of approximately 12,000 rare books and 1,300 linear feet of manuscript collections was completed by library personnel, who took shifts moving materials. In this case, space was reallocated within the main library, so the institution was altering an existing space rather than building from scratch. The authors list three primary areas of improvement made possible by the move: the first area was improved physical space with better furniture, equipment, security, access, and shelving practices; the second was improved communication about best practices for special libraries with patrons, library colleagues, institutional staff, and external contractors; and the third, better preservation conditions for collections. The move also allowed staff to conduct shelf reading to identify missing or misshelved items and items needing additional conservation treatment.

Multiple authors focus on the need for wide participation and flexibility during the process of a move. Thibodeau cautions that "[b]eing left out of the initial planning phases meant that the staff was left in a reactive rather than proactive mode." ${ }^{7}$ Once involved, however, "the library was viewed as a responsive and helpful partner. . . The architects and design team soon realized that the library staff were excellent resources for solving problems and generating alternative approaches." ${ }^{8}$ Likewise, Goldberg and Sproles state that "it is imperative to bring expertise from as many stakeholders as possible." ${ }^{9}$ The authors also note the importance of flexibility, concluding that "flexibility, expertise, and contingent planning by library staff to handle mini-crisis after mini-crisis allowed the moving teams to handle 355,000 items in just nine weeks, finishing just ahead of schedule." 10

Moving collection management records can also be a daunting task. Much of the literature focuses on moving finding aids rather than accession records; however, lessons can still be learned from concerns relating to timeline and process. Biswas and Skene describe the process of migrating finding aids to ArchivesSpace for an archives with two full-time staff. ${ }^{11}$ Many of the challenges identified in implementing the professional encoding standard, EAD, are not limited to smaller institutions. The authors describe previous attempts at creating EAD with Notepad++ with no resources for creating stylesheets or displaying the finding aids online. The institution also did not have the technical support to manage ArchivesSpace in-house but was able to purchase a hosted solution. It took a collaborative approach, with the project team consisting of staff from three different departments with expertise in metadata creation, digital projects, and archives. The team then determined that the catalogers had the ideal skill set for migrating data from finding aids created in Microsoft Word to ArchivesSpace and therefore created training materials, documentation, and workflows for the finding aids 
to pass between catalogers and special collections staff. The article was published in the middle of a three-year project to migrate the archives' 700 finding aids.

Calahan and Dietrick discuss the challenges of implementing ArchivesSpace at the University of Minnesota. ${ }^{12}$ Their organization started with over 5,000 EAD finding aids distributed among 15 units in the University of Michigan's Digital Library eXtension Service (DLXS). The institution chose a hosted solution and underwent a year-long contract negotiation process. A project team was formed, and "deliverable outcomes were divided in manageable tasks by breaking the work into four phases: (1) pre-EAD import into ArchivesSpace, (2) post-EAD import into ArchivesSpace, (3) finalizing implementation internally, and (4) developing the public interface and addressing access issues." ${ }^{13}$ The team decided not to enhance legacy finding aids at this time, and a training program was developed for archives staff. While the migration took six months, they describe the whole process as a "two-year journey," during which they learned "how implementing ArchivesSpace would integrally change so much of the work conducted in the department" and found the process "helped launch the department forward towards further consolidation and much needed centralization." ${ }^{14}$ The authors also note the need for internal publicity so that "reference librarians, library liaisons, instruction librarians-could navigate the public interface." 15

These case studies summarize some common principles for moving both physical archival records and digital collection management records. First, outside influences most often determine the timelines for physical moves. As large-scale moves or shifts are often precipitated by renovation, new construction, or a need to reallocate space, the timeline of the construction crews most heavily impacts the project timeline, and library and archives staff must adapt accordingly. Second, several of the case studies emphasize the need for library staff involvement in the planning process. This involvement is particularly critical for archives and special collections that have specific environmental and handling concerns. Finally, while the physical moves discussed in these articles all took place within a matter of months, the move of digital records in each instance was a multiyear process. For this reason, migrating to a new collections management platform also requires careful consideration and considerable staff time to be successful.

\section{Physical Cleanup and Inventory}

\section{New Staff/New Cleanup}

In 2015, Lilly Carrel, a senior-level archival manager, was hired for a one-year contract position to oversee an accessioning backlog. She also began the physical cleanup of collection storage spaces in Mullins Library prior to the move by managing a shelf-reading project for the primary storage area that tracked collections using a Microsoft Excel spreadsheet. During this phase, a number of collections from the backlog were accessioned, updated on the Excel shelf list, and entered into Archivists' Toolkit, the content management system used at the time for creating and maintaining accession records. While the archival manager left at the end of her contract in 2016, special collections 
was able to hire a permanent professional accessioning and processing archivist, Katrina Windon, to oversee collection management. With the physical move in mind, documenting the collections involved a systematic process to ensure every box that needed to be moved was prepared. The collections at the off-site storage building took precedence, as every single item from that building would have to be moved to the new off-site storage building.

\section{Shelf Reading, Identification, and Rehousing}

Before the move could take place, information about each collection needed to be entered into both ArchivesSpace (which had still not been implemented at that time) and the space management software (which had still not been selected) for the new off-site storage facility. Because the existing shelf list for the off-site storage building did not contain all the collection information needed before the move, the accessioning and processing archivist created an expanded spreadsheet to record the necessary information and to categorize collections according to the archivist responsible for managing each subject area. When the project team encountered collections with either vague or nonexistent identification information, they assigned those collections a category and the different collection managers a color for problem items. As the spreadsheet grew to very large proportions, it became a very useful tool for staff members to locate specific items that needed attention. During the first year, the shelf-reading and inventory project was primarily carried out by the accessioning and processing archivist overseeing manuscript collections, which made up the bulk of the collections at off-site storage, and by the university archivist, Amy Allen. Because staff members with other duties at the main library were conducting the project, each archivist had to dedicate blocks of their time to drive to the off-site storage with a student worker both for safety and assistance.

All boxes that were already properly housed, identified, and labeled simply had to be recorded in the spreadsheet. Many odd-sized items were inadequately housed or had no housing at all, and many specially sized boxes had to be ordered. When the archivists found collections with inadequate identification, they needed to conduct research in accession records at the main library and addressed the identification issues when they next returned to the off-site storage facility. This process became easier after the special collections' ArchivesSpace production instance was implemented in January 2018, and legacy data became easily searchable so that research could be conducted and accession records created at the off-site storage facility without having to travel to the main library.

\section{Coordinating with the Library-wide Project}

While significant progress was made during this initial phase, it became clear that additional time and staff would have to be devoted to this task to reach the libraries' deadline. The barcoding began slowly as part of the shelf-reading process in 2017 and increased substantially when it became a department-wide project in March 2018, as all staff with processing duties, along with any other members of special collections who were able, signed up for barcoding shifts. During 2018, all members of the libraries were 
required to contribute to the move in some manner. Most staff members participated in marking books in the main library to be moved, while a few volunteered to assist with special collections barcoding. Rehousing collections and labeling boxes continued right up to the move in the summer of 2018. All the boxes on shelves were moved first, but the building also contained flat files, filing cabinets, and oversized items that needed to be relocated. Most of the flat files were able to be moved as single units, while the oversized items and 3-D objects had to be individually tagged and wrapped.

As the new storage facility was intended to house both special collections and main library collection materials, space and tools had to be shared during this process. Regular circulation services were maintained during the preparation period, and, twice a day, a user services staff member came to the off-site facility to retrieve both main library and special collections materials requested by patrons. The storage facility also had only one mechanical lift, so staff members alternated their use of it, while staff engaged in shelf reading or barcoding temporarily shifted to allow other staff access to certain aisles within the movable shelving to retrieve materials for patrons. Later, the moving contractors also shared the space as they began to use the building as a staging space, which further complicated the process of executing the project while maintaining regular library services.

\section{Implementation of ArchivesSpace}

\section{A Nerw Collection Management System}

In 2017, special collections did not have a consolidated collections management system for creating accession records and finding aids, and therefore could not support the level of information (barcodes and detailed container-level information, particularly) needed for the (yet-to-be-selected) inventory management system to be used for the new off-site storage facility. Accession records were stored in three separate systems: records created prior to 2015 were in a no-longer-supported system, InMagic; most records from 2011 through 2017 were in Archivists' Toolkit (with some records entered into both systems between 2011 and 2015); and a variety of records, particularly those of accruals, were only available in paper accession files. Location information was stored separately-primarily in shelf-list spreadsheets, but also, in some cases, in card catalogs, or not at all. Finding aids were even less structured: less than half were in EAD and were stored on a webserver, along with less-structured formats including PDF and HTML; and hundreds more were only available in paper form in binders stored in the special collections reading room. The need for a new collections management system and a more consolidated approach to collections management was well known, and special collections staff had been planning for an eventual migration to ArchivesSpace starting as early as 2014, when a proposal was first sent to the libraries administration. Although the proposal was unsuccessful, staff began data cleanup in 2015, and the imminent physical move to off-site storage provided the crucial impetus to get the necessary approval and funding in a March 2017 proposal to implement a hosted instance of ArchivesSpace. 


\section{ArchivesSpace Host Vendor Selection}

Having received approval to implement ArchivesSpace, we began work on a vendor recommendation to submit to the libraries' administration. The field of available host vendors, excluding those who worked outside of the available geographic range, consisted of three primary options: LYRASIS, the home institution for ArchivesSpace; Atlas Systems, which already hosted the libraries' ILLIAD system for Interlibrary Loan requests; and LibraryHost, which, unlike the first two, is not a registered service provider for ArchivesSpace and therefore did not make the final round for consideration. While cost considerations were ultimately the deciding factor in selecting Atlas Systems as a vendor, special collections had a number of additional requirements including a vendor's ability to commit to the move-driven timeline and to migrate legacy content from two data sources (InMagic and Archivists Toolkit). Communication with vendors was crucial to the information-gathering process, as were discussions with institutions already using these vendors. Outsourcing the technical work of migration allowed staff to focus limited resources on the related metadata and inventory control work.

\section{Data Wrangling, Part One: Accession Records}

The metadata mapping process for InMagic data began in 2015 when the archival manager, Lilly Carrel, and the university archivist, Amy Allen, exported data from the InMagic database as a CSV file. Carrel began the mapping and cleanup of InMagic fields to the fields in the ArchivesSpace accession CSV template, and accessioning and processing archivist Katrina Windon continued this work in 2016. During the process, it became clear that the mapping process was going to be more difficult than they had anticipated. For instance, default values for ArchivesSpace required fields had not been used in InMagic; "dummy" values signaled when a value had been artificially applied to meet ArchivesSpace requirements (for instance, some of the accession records did not include a year); and Microsoft Excel formulas and VBA macros were needed to perform tasks like breaking out larger fields (like "Address") into the component fields (street, city, state, zip code) that ArchivesSpace requires. Like most institutions, special collections stewarded a large amount of messy data, and part of the migration preparation was deciding when it was acceptable for that data to remain messy (e.g., simply migrating the catch-all "Notes" field information to a "General Note" field instead of attempting to manually redistribute it). Perhaps one of the biggest complications was the issue of duplicate identifiers - most of which involved multiple accretions represented by a single accession number-which required research in the paper accession files to resolve.

Additionally, the duplicate accession records present in both Archivists' Toolkit and InMagic had to be compared and consolidated. The initial plan had been to import the InMagic data into ArchivesSpace using the ArchivesSpace accession CSV import function and the Archivists' Toolkit data through the Archivists' Toolkit migration plug-in. However, Atlas Systems has a custom migration tool for InMagic data spreadsheets, which meant that special collections staff were better able to refine the accession data, divert it into custom fields when needed, and address issues with test migrations that the department did not have the internal technical capacity or time to manage. 


\section{Data Wrangling, Part Two: Finding Aids}

Initially, the data migration project only targeted accession records; however, the department also wanted ArchivesSpace to be the system of record for its finding aids. Thus, while all the manipulation of already structured data was going on, staff began converting legacy finding aids (in PDF, HTML, Microsoft Word, and print formats) to EAD so that the finding aids could eventually be imported into ArchivesSpace. While some EAD conversion work had been done in the previous decade, a concerted push to complete the migration between 2017 and 2018 involved more than half of the department, as well as volunteers from other units of the libraries, as their schedules allowed. In the 10-month lead-up to the move, the EAD conversion project involved 23 people across three departments and resulted in the conversion of approximately 586 legacy finding aids. Since then, the project has cycled through personnel, added an external vendor, and converted more than a thousand additional finding aids. Most staff working on the project followed a workflow involving a combination of an in-house web form for collection-level description and Jason Ronallo's Steady application ${ }^{16}$ for collection inventories. After some initial test ingests into ArchivesSpace to identify problem areas, the accessioning and processing archivist worked with the libraries' web services team to perform bulk editing of existing EAD files that were not compliant with ArchivesSpace. Despite the immense amount of cross-unit collaboration on this project, staff were not able to complete the migration in advance of the move, so project managers decided to create "skeleton records" in ArchivesSpace for collections being moved before a complete resource record in ArchivesSpace could be created. For these skeleton records, top containers were associated directly with the collection-level record, rather than associated with collection components. Because this enterprise was to be an area of ongoing work for the department, the ArchivesSpace public user interface was not implemented until two years (and several more data cleanup projects) after the initial migration.

\section{Data Wrangling, Part Three: Top Containers and Location Information}

Once the accession and resource records had been created in ArchivesSpace, efforts began to associate top container information, including container profiles and barcodes, with the corresponding records. During this phase, staff added location information only for containers that would be moved to the new storage facility, and, because the facility's inventory management system would manage their specific locations, staff only applied a location code of "STOR" rather than any more granular information. A team of 15 people across four libraries departments entered into ArchivesSpace the information that staff had painstakingly been compiling in spreadsheets for the past two years. This team helped get everything completed on time, but not without some complications, including one particularly panic-inducing accidental deletion of the "Records Box" container profile that necessitated the host vendor reverting to a backup of the local ArchivesSpace instance. In addition to the safety net of the vendor's server backups, the spreadsheets also proved essential for performing quality control on the container and location information. 


\section{Bringing It All Together: Systems Integration}

While special collections staff were hard at work on the ArchivesSpace implementation, the libraries as a whole were exploring software solutions to serve as the inventory management system for the new storage facility. Ultimately, the Storage Facility Software Committee decided on CaiaSoft, a relatively new product designed specifically for libraries (while many competitors were designed for warehouses). At the time, no roadmap existed for integrating ArchivesSpace with CaiaSoft directly, nor did any of the ArchivesSpace default reports include all the fields needed for the inventory management system. After conversations with CaiaSoft and Atlas Systems, the implementation group decided to run SQL queries against the ArchivesSpace database, using an Open Database Connection (ODBC) that Atlas Systems set up, to return a custom report that included all the necessary metadata and container information to import into CaiaSoft, where data would be mapped to existing items based on barcodes. The accessioning and processing archivist worked with the libraries' web services librarian, Beth Juhl, to write basic MySQL queries in which location and top container creation date were used as ways to scope queries when running new reports to provide metadata for materials newly transferred to the storage facility. This workflow, while still requiring archivists to run reports and import CSV files into CaiaSoft, automated most of the process. In the future, we hope to explore more streamlined integration options including the use of an API. Having these structures in place has also allowed users of the ODBC to run a variety of other custom reports for everything from additional data cleanup projects to identifying potential donors. Implementing both a content management system and a storage management system at the same time presented challenges, but it also meant that the team was able to make initial implementation choices with an eye toward eventual systems integration, rather than needing to later integrate two systems with already entrenched workflows and policies.

\section{Collections on the Move}

\section{Library-wide Planning and Coordination}

The metadata and software components of the move were certainly the most complex for special collections to manage, but the logistics of the physical move also came with numerous complications and considerations, ranging from collection management decisions like determining what materials to move, to the logistical complexities of determining how to move them. While special collections staff was managing their portion of the move preparation, larger planning projects were also going on at a library-wide level. Beginning in March of 2017, the libraries had, at various stages of the project, a suite of at least eight committees and teams involved in coordinating planning. At least one staff member represented the special collections department on most of these committees, and this representation was crucial to ensuring that the department's specific needs were met. Throughout the planning process, advocating for the uniqueness of special collections materials and services was necessary, including the additional security and special handling protocols needed, the use of collection-level rather than item-level 
metadata, and the added complication of oversized materials that would never fit into the confines of standard book trays.

\section{What Stays and What Goes}

Both authors served as special collections representatives on the committee to determine what materials were to be moved to the new storage facility. We defined five criteria that special collections staff would use to evaluate collections: patron use, historical value, fragility, processing schedule, and recent accessions. Before the committee ever started work, the interim head of special collections drafted an initial list of collections that would remain onsite, which was circulated to the department for additional suggestions of materials that should be added or removed. Although the research services unit maintains usage statistics in spreadsheets and annual reports typically reference the top 10 collections used each year, tracking collection-level usage proved to be extremely challenging. For this reason, most of the initial usage decisions were based on the substantial institutional knowledge of the special collections' research services coordinator and other staff members, rather than on the limited data available. In addition to anticipated usage (whether by researchers or for upcoming processing projects), fragility and preservation considerations were also identified as criteria for prioritizing materials. Despite the initial criteria's heavy reliance on individual archivists' best judgment, these guidelines provided a framework to explain to administrators and researchers how archivists were making those judgments, as well as a basis for the more detailed usage-data-driven criteria to be implemented after the move to guide future decisions. The collection management work done as part of the move-particularly the container barcoding and adoption of an inventory management system to track container-level circulation-has enabled more data-driven decisions going forward, as the institution has since implemented LibInsight and Aeon. Special collections uses LibInsight, a Springshare product, to gather statistics related to processing, exhibits, instruction, outreach, and research and reference consultations. Special collections uses Aeon, an Atlas Systems product with built-in reporting capabilities that provide detailed usage statistics, as a circulation and request management system.

\section{Coordination with Movers and Off-site Storage Staff}

Special collections staff did considerable hands-on work and heavy lifting but did not physically transport any boxes from one facility to the other; that process the libraries contracted out to a vendor that handled the moving of all libraries' collection materials. Special collections staff wrote out handling procedures, met with moving company representatives, and, when possible, monitored the movers' work to ensure materials were handled with caution. Special collections staff also set up material handling training sessions with the libraries employees who would staff the new storage facility, most of whom had not worked with archival materials before. Just as in the initial library-wide planning meetings, it was important for staff to emphasize that the uniqueness of special collections materials necessitates unique handling practices, even if those practices are less efficient. Unanticipated problems still occurred. For instance, staff did not know 
that movers intended to move flat files by turning them on their sides until they did, and staff was left to remediate materials after the fact.

Some staff members worked with movers for more than a year through the end of the movers' contract as the last of the initial batch of materials was moved. In the year after the move, special collections staff continued to hold meetings with storage facility staff to improve joint workflows and ensure that special collections materials were being protected, but not at the expense of causing unnecessary work for partnering units. Special collections staff now uses Microsoft Teams to facilitate most communication with the storage staff and libraries shipping and receiving staff who receive materials from offsite storage at the loading dock and distribute them to relevant libraries units.

\section{Postmove Workflows}

Project teams developed dozens of new workflows to support each stage of the move preparation and data migration projects, yet still more workflows were needed to navigate the new postmove landscape. In special collections, these new workflows primarily impacted the research services and processing units. As each unit's staff have gained experience with the new systems, they continue to revise processes to address issues and seek further automation of routine activities whenever possible.

\section{Research Services}

Special collections had stored materials off-site since at least the 1980s, and it was wellestablished in documentation and on the department's website that researchers should submit requests at least two weeks in advance of their visit to ensure that their materials would be ready and waiting for them. For this reason, we expected a limited, even nonexistent, impact on researchers. Behind the scenes for research services staff, however, the impacts were more noticeable-generally in positive ways. For example, research services established "hold ranges" in some of the newly freed-up space in its onsite collections storage, where staff could hold boxes from the storage facility for long-term or upcoming research visits. Ensuring that materials retrieved from the storage facility were returned in a timely manner presented a challenge, so new workflows were established to run reports in CaiaSoft to locate containers that had a status of "in circulation" for more than six months so that they could be returned.

\section{Processing Unit}

At a time when processing archivists are committed to maximizing product at the expense of process, the move resulted in a lot more procedure being tacked onto existing processing workflows. Processors now barcode all containers and associate top container information in ArchivesSpace. Within six months of processing a collection, a processor evaluates the materials according to established selection criteria to determine whether the materials should stay onsite, be transferred to the storage facility, or be split up between locations. For any materials moving off-site, the processor is also responsible for ingesting them into CaiaSoft. This six-month window is intended to give processors 
some breathing room if they have competing priorities, but also as a time to gather preliminary circulation data. The implementation of these new, seemingly time-consuming, postprocessing workflows has granted special collections staff some very necessary, long-term benefits, including increased knowledge of the collections, better security, and the necessary space to grow collections.

\section{Conclusion}

\section{Loose Ends and Future Projects}

At times, we felt that the postmove cleanup projects would never end. The first order of business was to track down containers that had not been fully accounted for after the move. These included containers that had been moved with mis-scanned barcodes and thus weren't retrievable in CaiaSoft, and those that had been moved without barcodes (either because they never had one applied or because they fell off in transit). One of the primary remaining goals is to better integrate systems to further automate the exchange of metadata. Staff have also been engaged in a number of ongoing metadata cleanup projects, both for their benefit and in preparation for the implementation of the ArchivesSpace public user interface and Aeon, which requires expanding the location and container work done for containers being moved to all containers in the collection.

Ongoing challenges accompany the increased movement of collections across campus. Because special collections materials are transported alongside the main circulating materials between the main library and the annex four times a day, increased training on special handling procedures for archival materials became necessary. Additionally, special collections staff dedicated a permanent range in the onsite storage to temporarily store collections from the annex that researchers were using for an extended period of time and for classroom instruction or exhibits. Ensuring that materials are returned to the annex in a timely manner remains an ongoing challenge. Also, requests from patrons (both special collections and other materials) are rightly prioritized over staff requests. However, the daily volume of patron requests often leaves no room for requests from staff accessioning new collections, requesting large collections to process, or returning large collections that have been recently processed. It can take weeks or even months of staff requesting a few boxes a day to transfer large collections to and from offsite storage, and special collections continues to discuss with annex staff how to alleviate this issue.

\section{Lessons Learned}

For anyone about to undertake a similar project at their institution, numerous considerations will be specific to an institution's particular circumstances, but others are more generalizable. First, budget enough time to make plans, revise plans, implement plans, and revise those plans again. Even starting this process years in advance, special collections staff were still preparing materials right up until the moving day. Give any vendors or other third parties clear deadlines (that are earlier than the actual deadline), and remind them about those deadlines early and often. Also, be prepared for disasters, and 
remember that the people who disrupt the plans almost certainly do not intend to. Take time to breathe after completing a project of this magnitude-it's a major accomplishment!

Second, be sure to implement succession planning practices, and do not rely on a single person to complete any given task. As the planning and move described in this article took place during a significant transition in departmental staff, involving multiple people in the processes was crucial to maintain continuity. Making sure that multiple people have backups of digital work and administrative access to databases is also particularly important. At one point in our project, the administrator of the special collections' Archivists' Toolkit instance left without assigning a successor, and some back-end manipulation was necessary to regain access to the system.

Third, the scale of a project is important and should guide the decision-making process. Special collections staff were dealing with approximately 22,000 containers representing over a thousand collections. Not only was full participation by the department essential, but also seeking additional help from staff in other departments. More than 30 staff members and students were involved in some way, as well as a team of movers doing the physical move and a hosting service conducting the initial data migration. The large number of people involved played a major role in allowing the libraries to clean up data and physical spaces simultaneously. It meant staff could touch more records and boxes for identification and cleanup than some other institutions might be able to, thereby limiting the amount of postmove cleanup work and minimally affecting research services. However, the scale of personnel involved sometimes created additional challenges. For instance, staff had to schedule time in advance at the off-site storage facility to ensure enough space to work. The limitations of simultaneous editing of records in ArchivesSpace also quickly became evident as service slowed to a crawl at times. While there are many team-building benefits to an all-hands-on-deck collaborative approach to completing projects, it can also be exhausting, and finding ways to acknowledge the efforts being made is important. To that end, the University of Arkansas Libraries held a library-wide party near the end of the move, complete with home-grown awards like "Most Finding Aids Converted" and "Most Dedicated Barcoders" to celebrate staff contributions.

Finally, in general, oversharing is better than undersharing when major changes are occurring. Not everyone welcomes change, but transparency about why decisions are made can help ease the transition. Whenever possible, invite ideas from a larger group to inform major decisions. Special collections staff were not involved in the initial planning phases, and, therefore, provisions were not originally made for the special needs of archival materials and adjustments had to be made at a later stage. Especially for processes that affect everyday transactions within special collections, making decisions with input from staff made the transition smoother and workflows more feasible.

While every library and special collections department is different, many common factors exist across institutional move and data management projects like this one, and 
we hope that our experiences can serve as a resource to others, in the same way that reports and case studies from colleagues at other institutions provided a roadmap for the University of Arkansas Libraries.

\section{ABOUT THE AUTHORS}

Katrina Windon is the collections management and processing unit head for the University of Arkansas Special Collections. During the initial phases of the activities described in this article, she served as accessioning and processing archivist. As part of her duties, she manages the repository's ArchivesSpace instance. She has an MSIS from the University of Texas at Austin and is a certified archivist.

Amy L. Allen is the university archivist for the University of Arkansas Libraries Special Collections. She oversees collecting and processing for the University Archives unit in addition to contributing to reference and outreach activities and digital projects. She has an MLIS from the University of Alabama and a DAS certificate from the Society of American Archivists and is a certified archivist.

\section{NOTES}

1. Harvard University, “HD—The Harvard Depository: Offsite High Density Storage," https://hdep .library.harvard.edu/about-hd.

2. Matthew Goldberg and Claudene Sproles, "Moving a Large Collection Quickly: A Study in Chaos," Journal of Access Services 17, no. 1 (2020): 33-45, https://doi.org/10.1080/15367967.2019.1688159.

3. Ibid., 43.

4. Ibid., 39.

5. Patricia L. Thibodeau, "When the Library Is Located in Prime Real Estate: A Case Study on the Loss of Space from Duke University Medical Center Library and Archives," Journal of the Medical Library Association 98, no. 1 (2010): 25-28, https://doi.org/10.3163/1536-5050.98.1.010.

6. Colleen Hoelscher and Sarah Burke Cahalan, "Rethinking Special Collections Moves as Opportunities, not Obstacles," RBM: A Journal of Rare Books, Manuscripts, and Cultural Heritage 17, no. 2 (2017), https://rbm.acrl.org/index.php/rbm/article/view/16821/18411.

7. Thibodeau, "When the Library Is Located in Prime Real Estate," 27.

8. Ibid., 27.

9. Goldberg and Sproles, "Moving a Large Collection Quickly," 43.

10. Ibid., 44.

11. Paromita Biswas and Elizabeth Skene, "From Silos to (Archives)Space: Moving Legacy Finding Aids Online as a Multi-Department Library Collaboration," The Reading Room 1, no. 2 (2016): 65-84, https://readingroom.lib.buffalo.edu/PDF/vol1-issue2/From-Silos-to-Archives-Space.pdf.

12. Lisa Calahan and Kate Dietrick, "Setting the Stage and Keeping Sane: Implementing ArchivesSpace at the University of Minnesota," Journal of Archival Organization 13, nos. 3-4 (2016): 114-26, https://doi.org/10.1080/15332748.2018.1443502.

13. Ibid., 117.

14. Ibid., 122-23.

15. Ibid., 124 .

16. Jason Ronallo, "Steady," last updated 2016, http://steady2.herokuapp.com.

Correction: The originally published version of this article incorrectly stated that that University of Arkansas was established in 1971. It was established in 1871. 